\title{
ÁCIDO SALICÍLICO EM SEMENTES DE CALÊNDULA (Calendula officinalis L.) SOB DIFERENTES ESTRESSES ${ }^{1}$
}

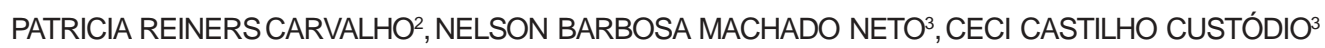

RESUMO - As plantas sofrem agressões por agentes bióticos e abióticos e apesar de não apresentarem defesas através de movimentos ágeis, podem ocorrer adaptações e profundas alterações no metabolismo celular, entre elas a síntese de proteínas de defesas, ativada através de mecanismos complexos. A aplicação exógena ou o estímulo à síntese endógena de ácidos orgânicos como o ácido salicílico, pode agir como indutor de proteínas de tolerância aos diferentes estresses, bem como para elevar a atividade de enzimas de desintoxicação celular, especialmente às envolvidas na degradação de radicais ativos oxigenados. O objetivo deste trabalho foi estudar o efeito do ácido salicílico sobre a germinação e o vigor de sementes de calêndula (Calendula officinalis L.) em condições ideais e sob estresse térmico e hídrico. As sementes foram colocadas para germinar em papel embebido em soluções crescentes de ácido salicílico (zero, 0,0125, 0,025, 0,05, 0,1 e $0,2 \mathrm{mM}$ ); medindo-se as variáveis: percentagem de germinação; índice de velocidade de germinação e primeira contagem da germinação. Ficou constatado através do teste de Tukey que apenas a germinação foi significativa, sendo que as melhores dosagens de sementes germinadas ficou entre 0,025 e 0,05mM de ácido salicílico. Três outros experimentos foram feitos, um com água acidulada aos $\mathrm{pH}$ respectivos às concentrações de ácido salicílico $(6,0 ; 4,8 ; 4,2 ; 3,6 \mathrm{e} 3,2)$, um com diferentes potenciais hídricos induzidos por manitol $(0 ;-0,3 ;-0,6 ;-0,9$ e $-1,2 \mathrm{MPa})$, e outro com temperaturas $\left(20,25,30 \mathrm{e} 35^{\circ} \mathrm{C}\right)$. O ácido salicílico na dose de $0,025 \mathrm{mM}$ interferiu positivamente na percentagem de germinação e no índice de velocidade de germinação de sementes da calêndula em condições ideais e sob efeito de estresse hídrico e térmico a $35^{\circ}$.

Termos para indexação: resistência sistêmica adquirida, estresse hídrico, germinação

\section{SALICYLIC ACID IN MARIGOLD SEEDS (Calendula officinalis L.) UNDER DIFFERENT STRESSES}

\begin{abstract}
Marigold (Calendula officinalis L.) is an important medicinal and decorative plant also used in cooking and in the manufacturing of cosmetic and phytotherapic products. The plants are susceptible to biotic and non biotical aggression and although they do not present defense through agile movement, they can present deep modifications in the cell metabolism as defence including protein synthesis activated by single molecules or complex mechanisms. The exogenous application or the synthesis stimulus of organic acids such as salicylic acid may act as an inductor of tolerance protein to different biotical or non biotical stresses increasing the detoxification enzyme activity, specially those involved in the degradation of reactive oxygen species. The aim of this study was to investigate the role of salicylic acid in the germination and vigour of marigold seeds (Calendula officinalis L.) in ideal or stress conditions. Seeds were put to germinate on paper moistened with SA (zero; $0.0125 ; 0.025 ; 0.05 ; 0.1$ and $0.2 \mathrm{mM}$ ). Germination, first germination count and germination speed index were measured. Only germination was significant, and the best doses were 0.025 and $0.05 \mathrm{mM} \mathrm{SA}$. Three other experiments were carried out, one with acid water, adjusted to the $\mathrm{pH}$ of the related salicylic acid solutions $(6.0 ; 4.8 ; 4.2 ; 3.6$ and 3.2$)$, one with different water
\end{abstract}

\footnotetext{
${ }^{1}$ Submetido em 14/12/2005. Aceito para publicação em 08/11/2006. Parte da dissertação de Mestrado do curso de Produção Vegetal da UNOESTE.

${ }^{2}$ Eng $^{a}$ Agr $^{\text {a }}$, Esp., Prof ${ }^{a}$ aluna de Mestrado da UNOESTE. patriciareiners@ superig.com.br
}

\footnotetext{
${ }^{3}$ Eng $^{\circ} \mathrm{Agr}^{\circ}$, Dr., Profs. do Departamento de Biologia Vegetal e Fitossanidade e do mestrado em Produção Vegetal, UNOESTE, Rod. Raposo Tavares Km 572, 19067175, Presidente Prudente - SP.
} 
potentials, induced by mannitol $(0 ;-0.3 ;-0.6 ;-0.9$ and $-1.2 \mathrm{MPa})$ and one with different temperatures $(20$, $25,30 \mathrm{e} 35^{\circ} \mathrm{C}$ ). The salicylic acid treatment of $0,025 \mathrm{mM}$ was positive for germination and the germination speed index of Calendula officinalis Marigold seeds under ideal conditions and water stress at the temperature of $35 \mathrm{C}$.

Index terms: systemic acquired resistance, water deficit, germination

\section{INTRODUÇÃO}

A calêndula (Calendula officinalis L.) pertencente à família Asteraceae, é importante pelo seu uso como planta medicinal e ornamental. A busca crescente pelo desenvolvimento sustentável e melhorias na qualidade de vida também envolvem o despertar de tecnologias para produção de espécies vegetais cada vez em maiores quantidades e com menores agressões ao meio, com essa conscientização cada vez maior da população, no tocante a conservação do ambiente, a utilização de agroquímicos começa a ser repensada e buscas por novas tecnologias, voltadas à proteção das plantas contra os agentes bióticos e abióticos, ganham um novo impulso. Nesse contexto, de exploração sustentável e proteção de plantas, além de novos produtos fitoterápicos, podemos inserir a indução de resistência vegetal, que pode ser vista como de ocorrência natural, ou podendo ser induzida por fatores bióticos ou abióticos, os quais precisam ser decifrados para serem usados em favor de produtos eficientes e ambientalmente corretos na busca de maior produtividade com qualidade (Gazim, 2005).

As plantas, assim como todos os outros seres vivos, sofrem freqüentemente agressões causadas por agentes bióticos e abióticos. Apesar dos vegetais não apresentarem defesas, através de movimentos ágeis, sabe-se que podem ocorrer adaptações e profundas alterações no metabolismo celular, entre elas a síntese de proteínas de defesas, expressa por genes específicos, ativados através de mecanismos complexos (Busam et al., 1997; Pinheiro et al., 1999). Tais proteínas exercem vários papéis na resistência e sobrevivência da planta, de forma direta (combatendo o agente agressor) ou indireta (mantendo a estrutura e as funções celulares).

Esse elaborado sistema de defesa e adaptação das plantas pode atuar de três formas: a) resistência constitutiva, inespecífica ou estática, dependendo do pesquisador que a elas se refere, ocorre mesmo sem a ação de agentes agressores, recebida por herança genética, tornando as plantas imunes à determinados patógenos (Goto, 1990; Sticher et al., 1997); b). resistência localizada, ativada no ponto onde ocorre à agressão, e c) Resistência Sistêmica Adquirida (SAR Systemic Acquired Resistance) que protege a planta contra ataques subseqüentes.

SAR e Indução de Resistência Sistêmica (ISR - Induced Systemic Resistance), são fenômenos distintos (Sticher et al., 1997) mas fenotípicamente semelhantes, onde plantas, após exposição a um agente indutor, têm seus mecanismos de defesa ativados não apenas no sítio de indução como também em outros locais dele distantes, de forma mais ou menos generalizada. Para autoridades mundialmente reconhecidas na área de indução de resistência em plantas (Métraux et al. 1991; Sticher et al., 1997) parece ser consensual que SAR e ISR são fenômenos distintos quanto à forma através da qual são induzidos, desencadeados e governados por mecanismos bioquímicos diferentes, mas bastante semelhantes no que concerne ao resultado fenotípico final, expressando-se sob forma de indução de resistência com caráter de sistemicidade.

Embora com pequenas discordâncias Métraux et al., (1991) têm assumido que SAR envolve o acúmulo de PRPs (Proteínas Relacionadas com Patogênese) como mecanismos induzidos de defesa da planta, sendo a indução salicilatodependente (White, 1979; Métraux et al., 1991; Palva et al., 1994; López-López et al., 1995; Andarwulan e Shetty, 1999) e podendo resultar em alterações na planta que a sofreu; geralmente é induzida por patógenos ou ativadores químicos.

No caso de ISR, não há acúmulo de PRPs, a planta que sofreu indução não exibe alterações, o agente indutor é usualmente um microorganismo não-patogênico e sua indução não é salicilato dependente, parecendo haver uma outra rota de sinalização mais associada a jasmonatos e etileno (Sticher et al., 1997).

Radicais livres são formados sob condições de estresse oxidativo bem como pelas reações normais da cadeia de transporte de elétrons, mas que são altamente reguladas (Chaoui et al., 1997; Mazhoudi et al., 1997; Greggains et al., 2000), todavia esta regulação pode ser perdida se o estresse for mais severo aumentando consideravelmente a produção de radicais livres que podem levar a uma cascata de evento 
que começando com a peroxidação de lipídeos, avançam para degradação de membranas e para morte celular (Greggains et al., 2000). De acordo com Foyer et al. (1997) o aumento nos oxidantes celulares pode levar a super expressão de genes de enzimas de desintoxicação como as superóxido dismutases (SOD) (Giannopolitis e Ries, 1977), catalase (CAT), peroxidase (PRX) e enzimas do ciclo ascorbato-glutationa (Sung e Jeng, 1994; Bailly et al, 1998) como parte de uma estratégia requerida para superar o estresse oxidativo (Foyer et al., 1997).

$\mathrm{O}$ composto $\mathrm{H}_{2} \mathrm{O}_{2}$ possui diversas funções dentro da célula desde a produção de radicais livres até lignificação e produção de compostos fenólicos, bem como atuando como gatilho para as respostas SAR (Hammerschmidt e Kuc, 1982; Siegel, 1993; Hammerschmidt e Kuc, 1995; Benhamou e Nicole, 1999; Jung et al., 2000; McCue et al., 2000) onde o ácido salicílico pode ser responsável por disparar a resposta SAR inibindo peroxidases específicas.

O termo elicitor biológico, usualmente se refere a macromoléculas, originadas tanto das plantas, como dos patógenos, as quais são capazes de estimular as respostas das plantas a patógenos. Uma ampla gama de compostos, incluindo oligossacarídeos, glicoproteínas e peptídeos, pode mediar a indução das reações de defesa nas plantas (Jung et al., 2000, Kúc, 2000; Benhamou e Nicole, 1999). De forma análoga, a resistência ao frio ou aos choques de calor podem ser aumentados por elevação na concentração de compostos fenólicos (Rivero et al., 2001) ou por alguns aminoácidos envolvidos na síntese de fenólicos (Machado Neto et al., 2004b)

O objetivo deste trabalho foi estudar o efeito do ácido salicílico sobre a germinação e o vigor de sementes de calêndula em condições de estresse hídrico e térmico.

\section{MATERIALE MÉTODOS}

O presente estudo foi conduzido no Laboratório de Análise de Sementes da (UNOESTE) Universidade do Oeste Paulista, em Presidente Prudente (SP), no período de outubro de 2002 a agosto de 2004.

Foram utilizadas sementes de calêndula (Calendula officinalis L). provenientes de São Paulo. Estas foram homogeneizadas e caracterizadas inicialmente através da determinação do grau de umidade, massa de 100 sementes, teste de germinação, classificação de vigor, comprimento de hipocótilo e de raiz, massa seca de parte aérea e de raiz.

Massa de 100 sementes: determinada usando-se 8 repetições de 100 sementes por lote (Brasil, 1992).

Teste de germinação: conduziu-se com quatro repetições de 25 sementes por tratamento, (em duas folhas de papel para germinação), acondicionadas em gerbox acrílico umedecidas com $12 \mathrm{~mL}$ de água e borrifados com água a cada dois dias, colocados em germinador tipo 'Mangelsdorf' a $25^{\circ} \mathrm{C}$ e fotoperíodo de oito horas (Brasil, 1992). As contagens de germinação foram feitas após o terceiro dia da semeadura até os 21 dias e a percentagem de germinação foi calculada levando-se em consideração as plântulas normais (Brasil, 1992).

\section{Experimento 1}

Foi preparada uma solução matriz de ácido salicílico (AS; 138,12 g.mol ${ }^{-1}$ ) de $0,2 \mathrm{mM}$ e através de diluições sucessivas em água destilada, foram atingidas as concentrações 0,$1 ; 0,05$; 0,025 e $0,0125 \mathrm{mM}$ utilizadas em todos os experimentos.

As sementes foram acondicionadas em embalagens de acrílico (gerbox), sobre duas folhas de papel para germinação e umedecidas com $12 \mathrm{~mL}$ das soluções de AS nas doses de 0,$0 ; 0,0125 ; 0,025 ; 0,05 ; 0,1$ e $0,2 \mathrm{mM}$ e colocadas no germinador nas mesmas condições do teste de germinação. Nos 21 primeiros dias após o início do surgimento das plântulas, foi avaliado o índice de velocidade de germinação. Considerouse como germinada, uma plântula normal com, no mínimo, 2 $\mathrm{cm}$ de altura. Para o cálculo foi utilizada a fórmula citada por Nakagawa (1999).

Comprimento de hipocótilo e de raiz, massa seca de parte aérea e de raiz: As avaliações foram conduzidas inicialmente nas mesmas condições do experimento 1. Ao sétimo dia, as plântulas normais foram avaliadas medindo-se o comprimento do hipocótilo e da raiz, a massa seca da parte aérea (sem os cotilédones) e a massa seca da raiz (Nakagawa, 1999).

\section{Experimento 2}

$\mathrm{O} \mathrm{pH}$ das amostras de AS nas concentrações de zero, 0,0125, 0,025, 0,05 e 0,1mM foi aferido em pHmetro e com base nestes valores foram preparadas soluções de ácido clorídrico (HCL - 36,47g.mol-1) até os mesmos níveis de $\mathrm{pH}$ das amostras de AS (6,0; 4,8; 4,2; 3,6 e 3,2). As sementes de calêndula foram acondicionadas em gerbox e seguindo as mesmas condições do experimento 1. As contagens de germinação foram feitas após o terceiro dia da semeadura até os 21 dias e a percentagem de germinação foi calculada levando-se em consideração as plântulas normais (Brasil, 1992). Foram medidas as variáveis: percentagem de germinação $(G)$; índice de velocidade de germinação (IVG) e primeira contagem da germinação (PC).

\section{Experimento 3}

A germinação foi executada como no experimento 2, porém com temperaturas constantes de $20,25,30$ e $35^{\circ} \mathrm{C}$. As 
contagens de germinação foram feitas após o terceiro dia da semeadura até os 21 dias e a percentagem de germinação foi calculada levando-se em consideração as plântulas normais (Brasil,1992). Foram medidas as variáveis: percentagem de germinação (G); índice de velocidade de germinação (IVG) e primeira contagem da germinação (PC).

\section{Experimento 4}

As sementes foram pré-condicionadas em soluções de AS nas doses de 0,0;0,025 e 0,05mM e colocadas para secar ao ar. Ao atingirem a umidade inicial, foram colocadas para germinar nas mesmas condições de temperatura e fotoperiodo dos experimentos anteriores em diferentes potenciais hídricos $(0 ;-0,3 ;-0,6 ;-0,9$ e $-1,2 \mathrm{MPa})$ induzidas por diferentes concentrações de manitol conforme Machado Neto et al. (2004a). As contagens de germinação foram feitas após o terceiro dia da semeadura até os 21 dias, separando-se as plântulas que obtinham pelo menos dois centímetros de raiz e a percentagem de germinação foi calculada levando-se em consideração as plântulas normais (Brasil,1992) e para a primeira contagem de germinação foram consideradas as plântulas normais obtidas aos três dias após a semeadura e que apresentaram pelo menos dois centímetros de comprimento. Foram medidas as variáveis: percentagem de germinação (G), índice de velocidade de germinação (IVG) e primeira contagem da germinação (PC).

\section{Análise dos resultados}

Os experimentos foram conduzidos com delineamento inteiramente casualizados e os resultados de percentagem de germinação e primeira contagem de germinação foram transformados em arc seno $(\mathrm{X} / 100)^{0,5}$, o comprimento do hipocótilo e raiz, e a massa seca da parte aérea e de raiz não foram transformados. Os dados foram analisados com a ajuda do software SISVAR, usando o teste F para análise de variância, o teste Tukey a 5\% para a comparação múltipla de médias. Os efeitos de concentração foram analisados por regressão polinomial. Os resultados de determinação da massa de 100 sementes e de grau de umidade não foram analisados estatisticamente.

\section{RESULTADOS E DISCUSSÃO}

A Figura 1, mostra que os tratamentos com diferentes doses de ácido salicílico (AS) e em condições ideais de temperatura e umidade não apresenta diferenças significativas no tocante à massa seca da raiz das plântulas. Todavia a massa seca da parte aérea das sementes tratadas com AS apresentaram decréscimo nos valores deste parâmetro. Isto pode ser devido ao efeito fitotóxico do tratamento como citado por Palva et al.(1994).

Houve diferença significativa para os índices de velocidade de germinação (Figura 2), sendo que os maiores valores situam-se entre 0,025 e $0,05 \mathrm{mM}$, mostrando a diminuição da velocidade da germinação das sementes de calêndula a partir dessas doses de AS. Segundo Takaki e Rosim (2000), o ácido acetil salicílico provoca sincronização da germinação de Raphanus sativus e o mesmo efeito ocorreu com calêndula

$\bullet$ MSPA $\square$ MSR

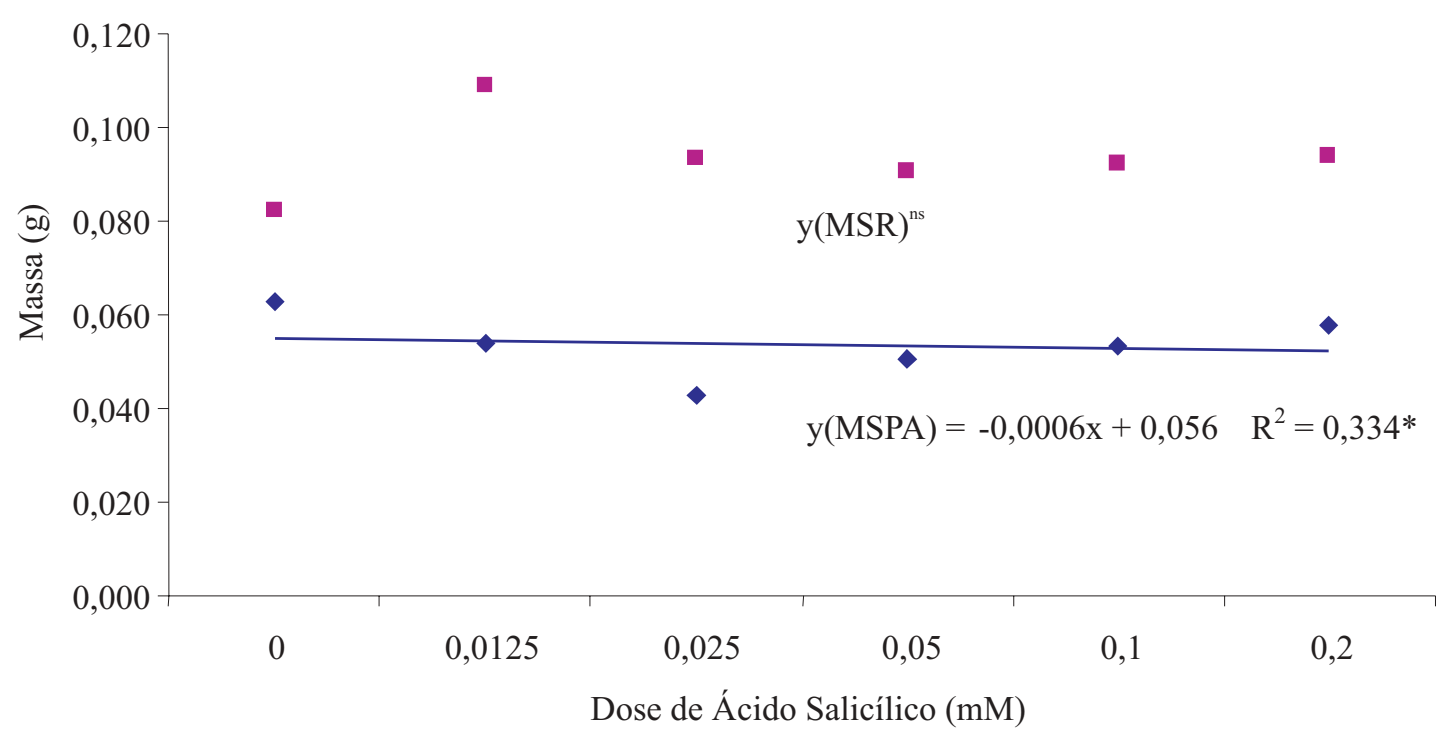

FIGURA 1. Massa seca de parte aérea (MSPA) e de raiz (MSR) de calêndula (Callendula officinalis L.) submetidas a diferentes doses de ácido salicílico. UNOESTE, Presidente Prudente, SP, 2004. 


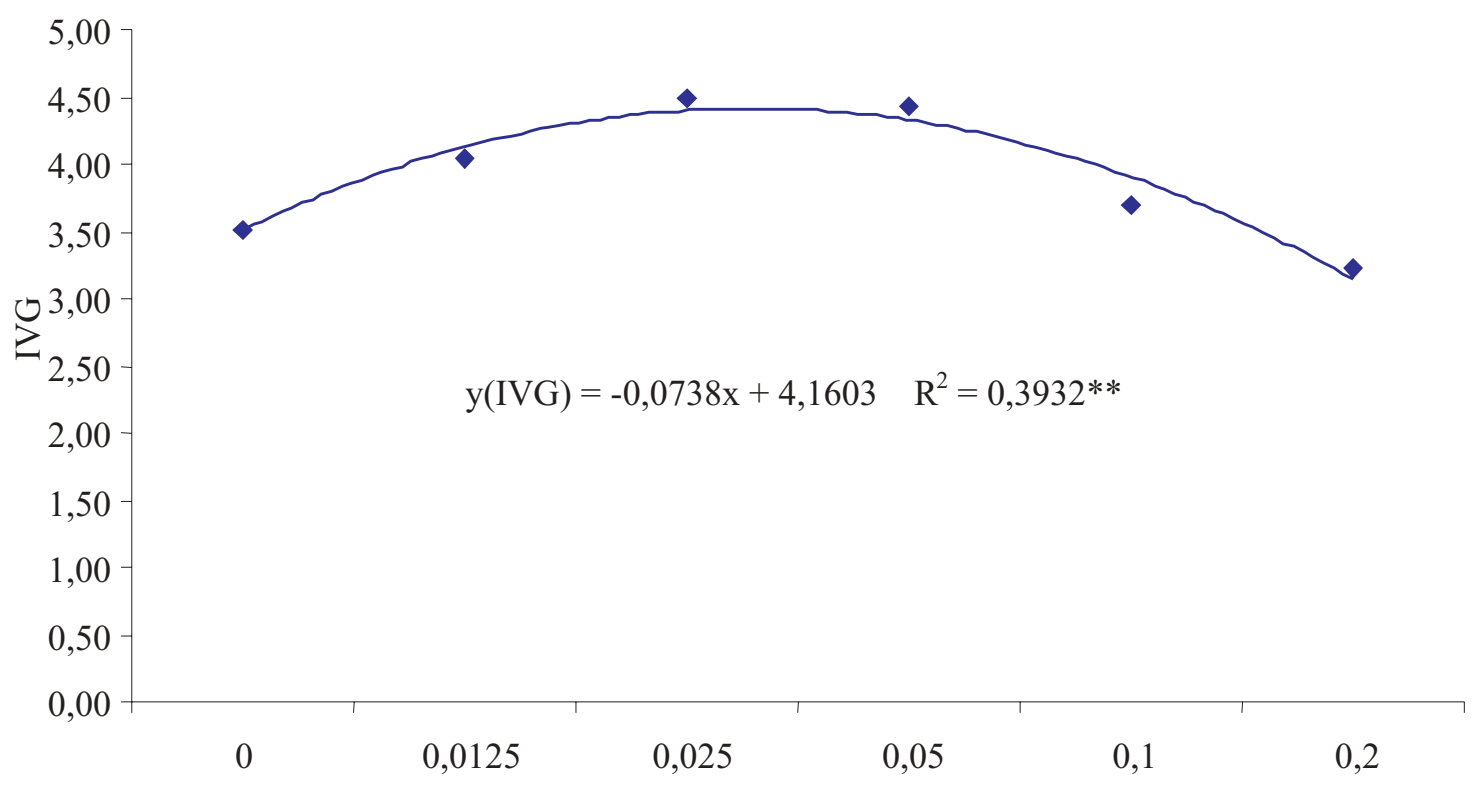

Dose de Ácido Salicílico (mM)

FIGURA 2. Índice de velocidade de germinação (IVG) de sementes de calêndula (Callendula officinalis) submetidas a diferentes doses de ácido salicílico. UNOESTE, Presidente Prudente, SP,2004.

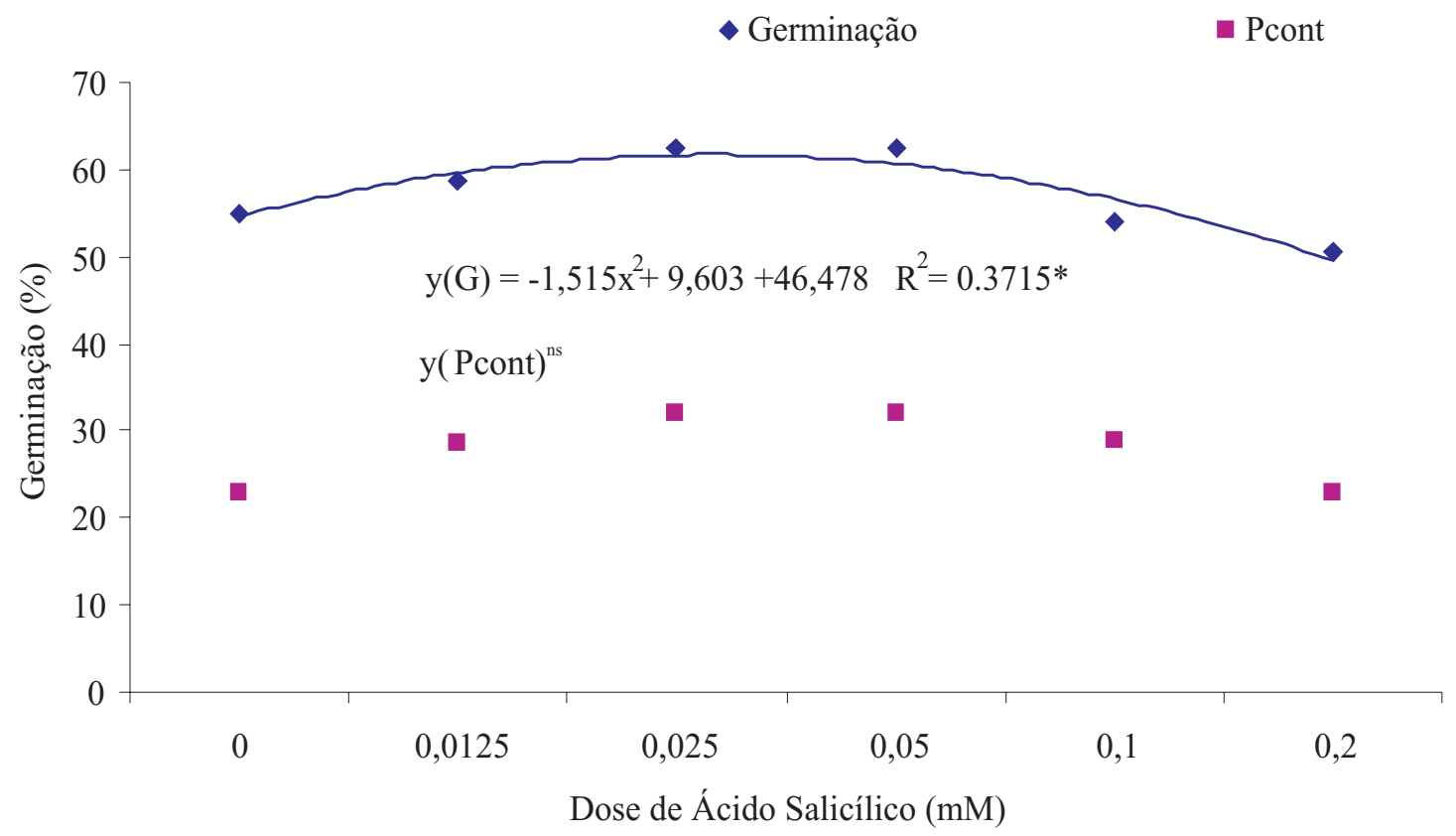

FIGURA 3. Germinação (\%) e primeira contagem de germinação (Pcont) de sementes de calêndula (Callendula officinals $L$.) submetidas a diferentes doses de ácido salicílico. UNOESTE, Presidente Prudente, SP,2004.

nas doses de 0,025 e $0,05 \mathrm{mM}$ utilizadas neste trabalho.

Apesar de os testes de germinação e primeira contagem terem tendências similares (Figura 3) não houve diferença significativa na primeira contagem, talvez devido ao fato da plântula ainda não ter tido tempo hábil de resposta ao AS. Na hipótese deste estar induzindo Resistência Sistêmica Adquirida - SAR, observa-se ainda que a germinação foi significativa, já que a mesma é realizada aos 21 dias. As plãntulas provavelmente obtiveram tempo para que o AS pudesse agir e assim ativar o sistema. Dessa forma, as melhores doses 
detectadas sementes de calêndula germinadas situaram-se entre 0,025 e $0,05 \mathrm{mM}$ de AS, mesmo em condições ideais de temperatura e umidade.

De acordo com a Figura 4 observa-se que para os parâmetros número de folhas, comprimento da parte aérea e comprimento da raiz não houve diferenças significativas para os tratamentos com AS. Estes testes foram efetuados ao sétimo dia da germinação, talvez as proteínas de tolerância ainda não estivessem atuando, sendo o SAR um mecanismo de defesa acionado por indutores (Hammerschmidt e Kuc, 1982; Métraux et al. 1991; Palva et al. 1994; López-López et al., 1995; Sticher et al. 1997; Kúc, 2000; McCue et al., 2000).

De acordo com McCue et al.(2000) e Andarwulan e Shetty (1999), um meio com baixo $\mathrm{pH}$ pode estimular a síntese fenólica e aumentar a rigidez do tecido através de lignificação. A estimulação da síntese fenólica, através de baixo $\mathrm{pH}$, suporta a hipótese de que o crescimento e elongação de células, induzida por acidez, pode ser regulada através da via das pentoses fosfato. Esta via pode estar ligada à estimulação do metabolismo de prolina, em resposta ao meio ácido ou aplicação de ácido salicílico, baseada em concomitante estimulação de glucose-6-fosfato-desidrogenase e aumento do conteúdo de prolina. As diferenças de acidez (Figura 5) não alteraram as avaliações de percentual de germinação e IVG, sendo assim extinta a possibilidade do efeito ser devido à acidez, confirmando-se o efeito de AS em sementes de calêndula.

Segundo McCue et al. (2000), várias formas de combate ao estresse são citadas, entre elas a aplicação exógena ou estímulo à síntese endógena dos ácidos orgânicos, salicílico, ascórbico e cítrico, sendo que destes o primeiro pode agir como indutor de proteínas de tolerância ao estresse (SAR). Nos tratamentos com AS na concentração de $0,025 \mathrm{mM}$, houve melhora significativa no percentual de germinação e no IVG

$\square \mathrm{CPA} \bullet \mathrm{CR} \triangle \mathrm{NF}$

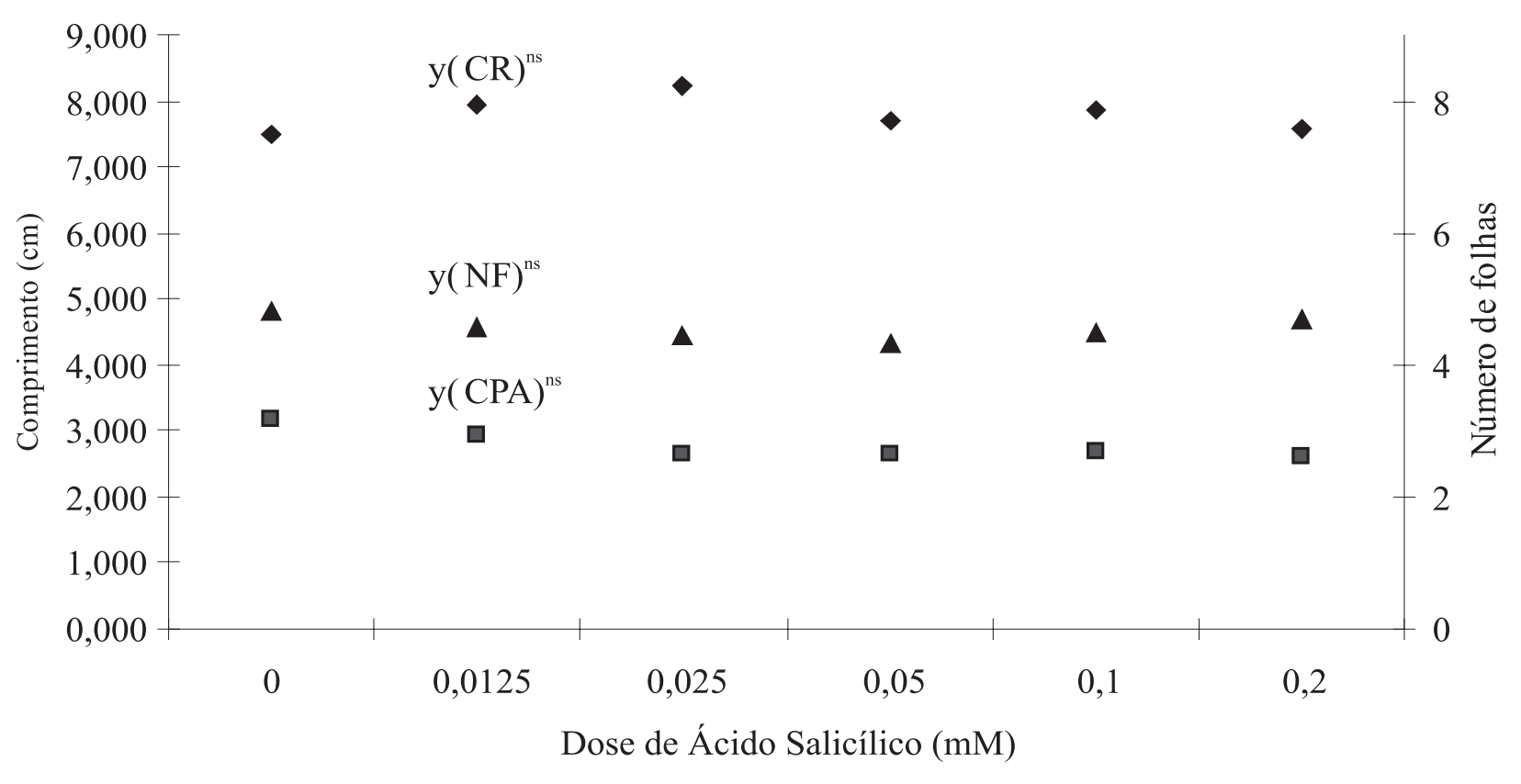

FIGURA 4. Número de folhas (NF) e comprimento de parte aérea (CPA) e de raízes (CR) de plântulas de calêndula (Calendula officinalis $L$.) submetidas a diferentes doses de ácido salicílico .UNOESTE, Presidente Prudente, SP,2004. 


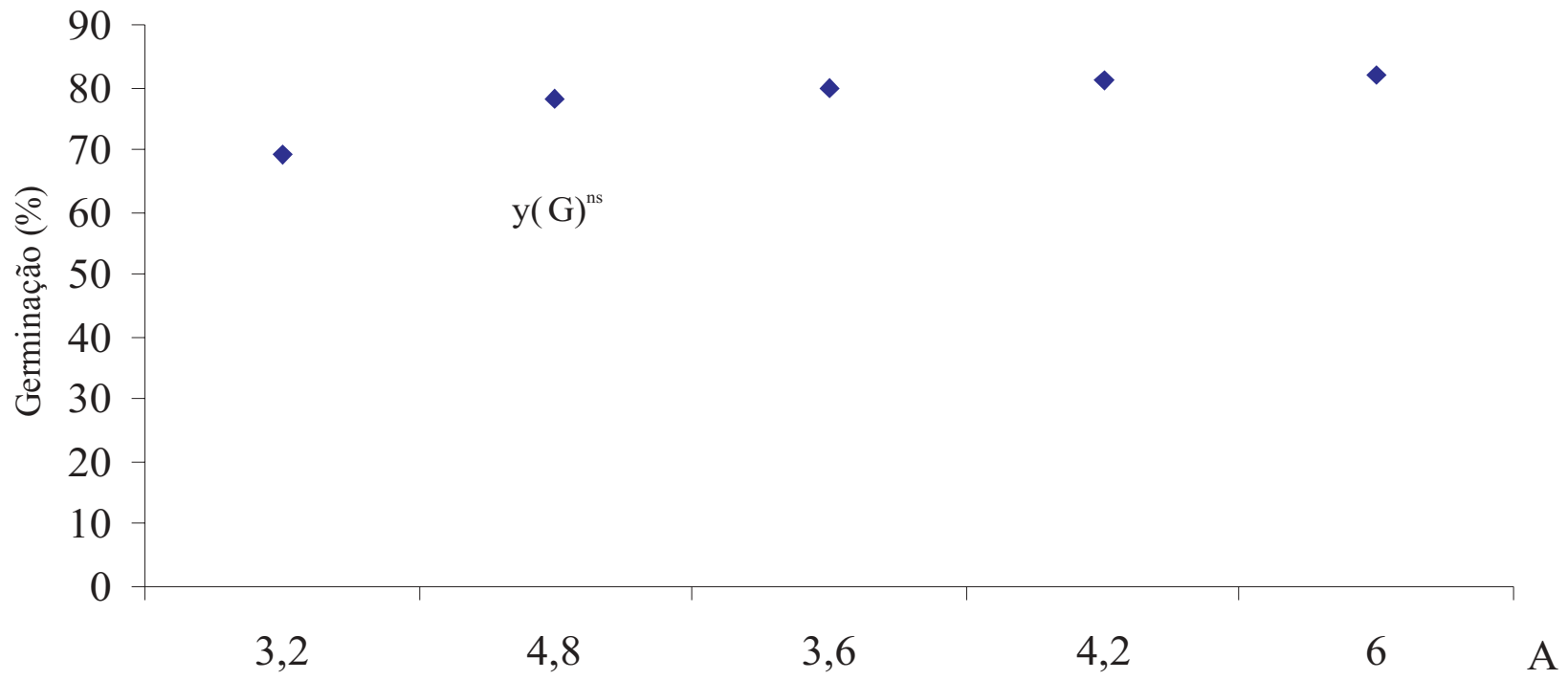

$\mathrm{pH}$ do substrato

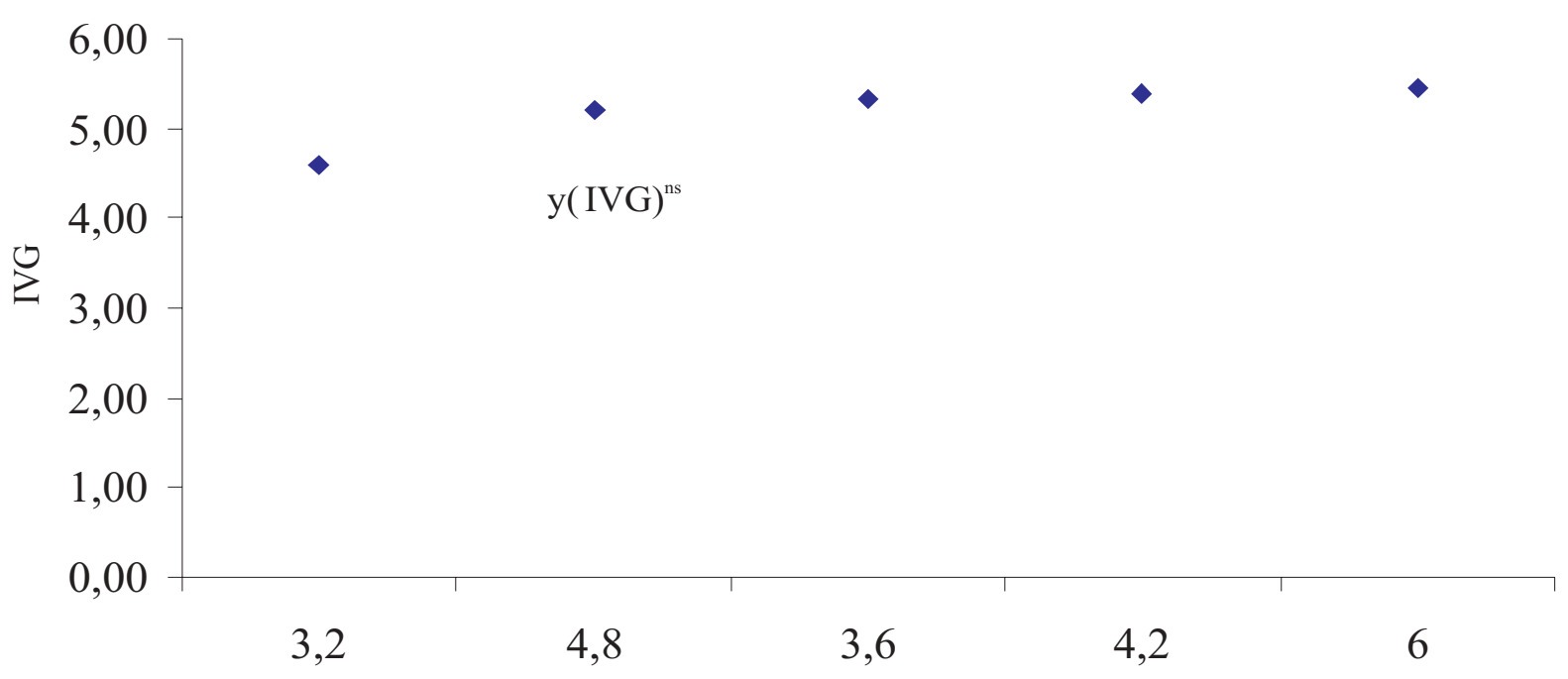

$\mathrm{pH}$ do substrato

FIGURA 5. Germinação (\%) e índice de velocidade de germinação (IVG) de sementes de calêndula (Calendula officinalis $L$.) submetidas a diferentes pH. UNOESTE, Presidente Prudente, SP, 2005.

de sementes de calêndula sob efeito de estresse hídrico (Figuras 6 e 7). Isto pode ser devido à resposta das sementes ao AS, que poderia ter induzido proteínas SAR fazendo com que as sementes tivessem uma resposta superior à germinação em água.
Tanto o percentual de germinação como o IVG de sementes de calêndula, reagiram positivamente sob efeito de estresse térmico a $35^{\circ} \mathrm{C}$, quando submetidas às doses de 0,025 e 0,05 mM de AS (Figuras 8 e 9), comprovando assim o efeito do AS em condições de estresse térmico, e mesmo em 


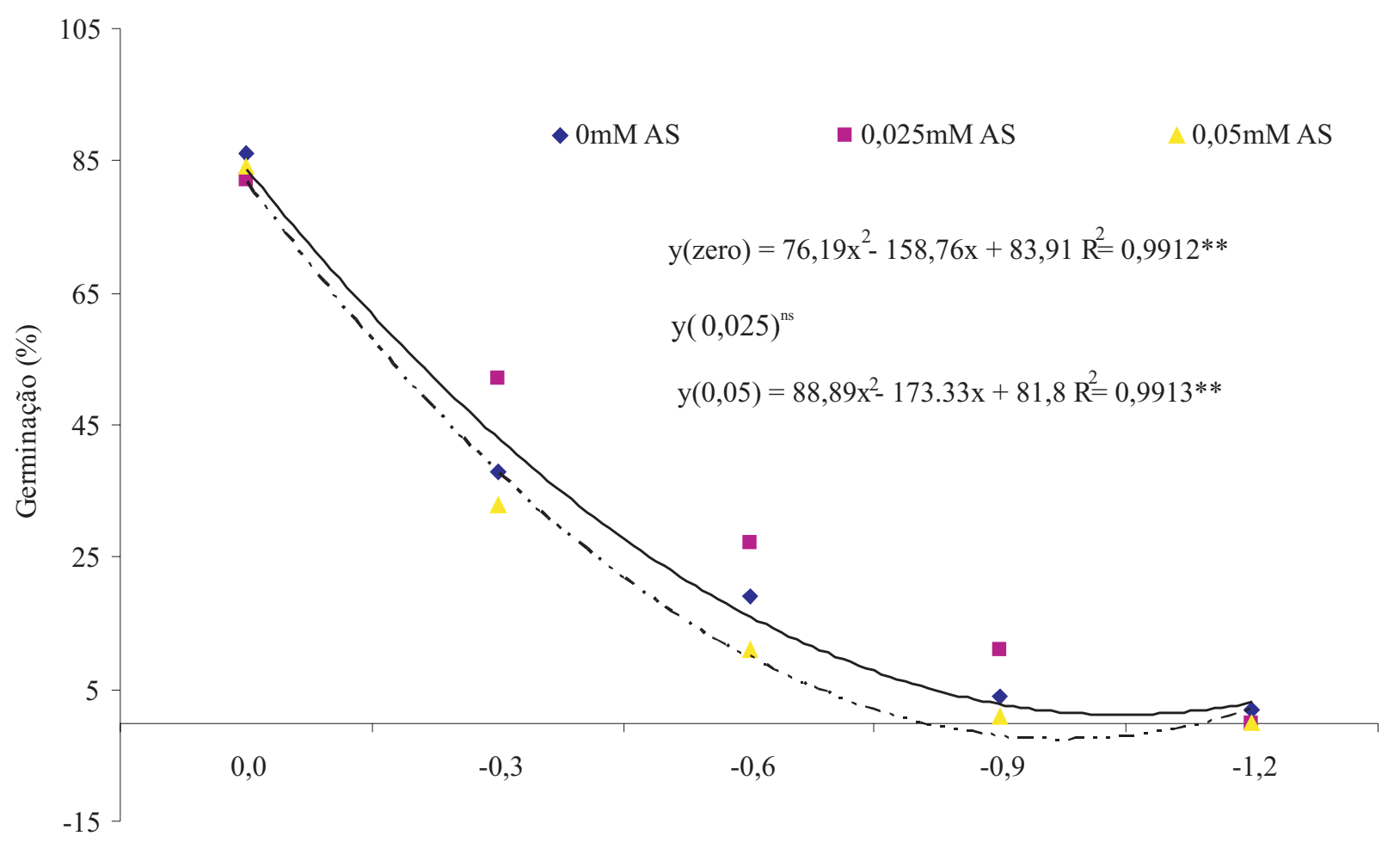

Potencial osmótico (MPa)

FIGURA 6. Germinação (\%) de sementes de calêndula (Calendula officinalis L.) submetidas a diferentes concentrações de ácido salicílico sob estresse hídrico.UNOESTE, SP, Presidente Prudente, 2005.

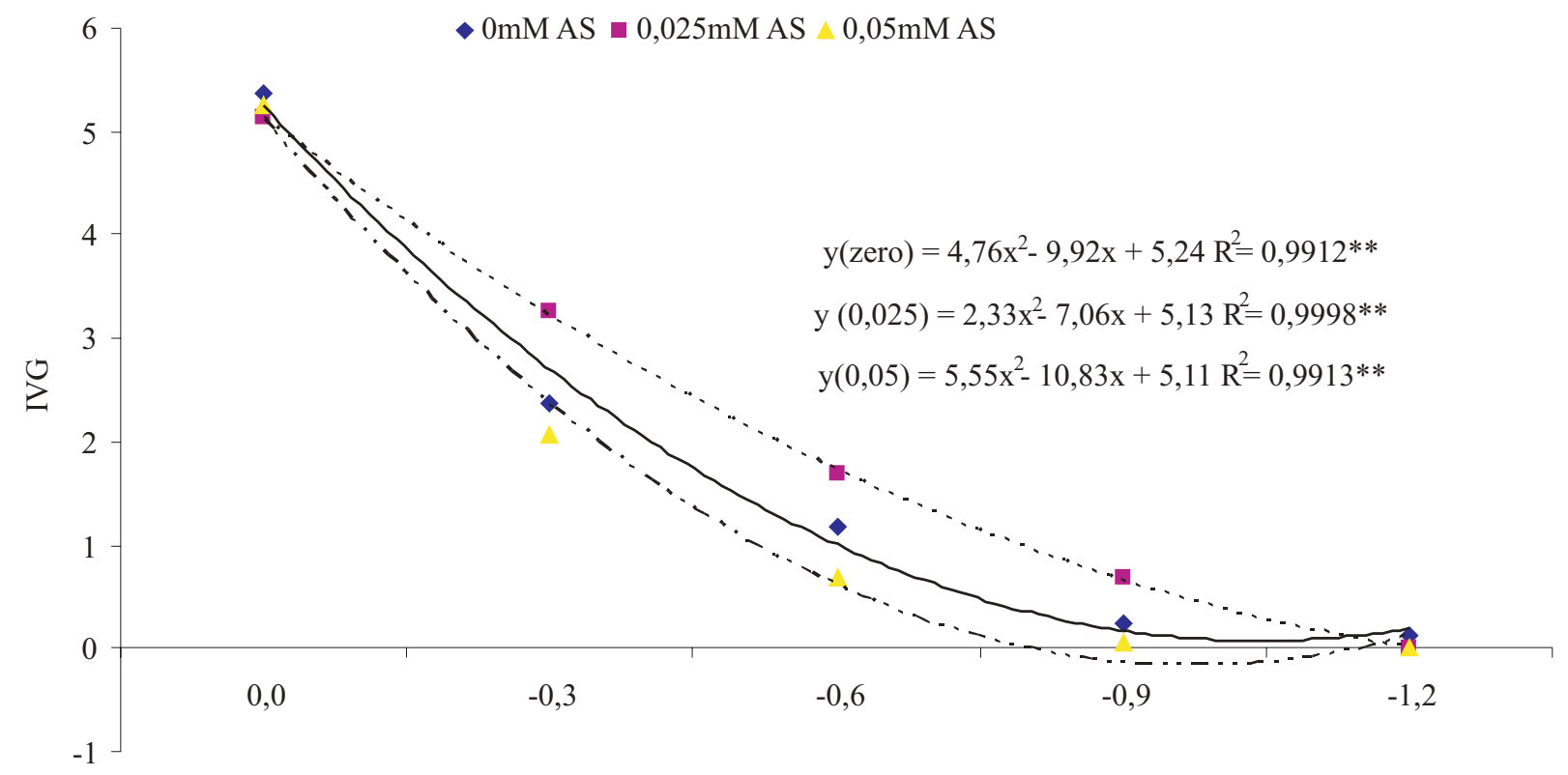

Potencial Osmótico $(\mathrm{MPa})$

FIGURA 7. Índice de velocidade de germinação (IVG) de sementes de calêndula (Calendula officinalis $L$.) submetidas à diferentes concentrações de ácido salicílico sob estresse hídrico. UNOESTE, Presidente Prudente, SP,2005. 


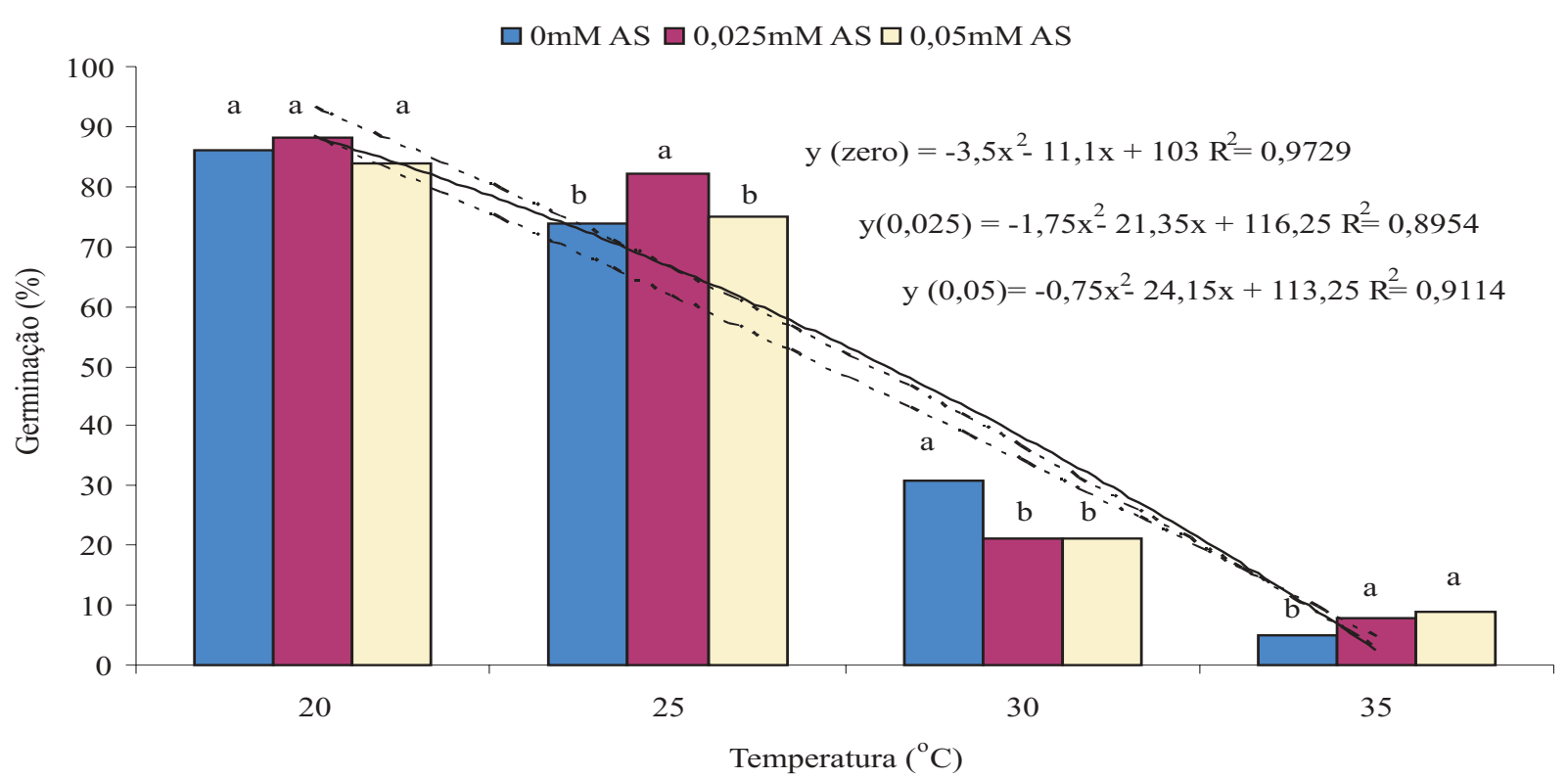

FIGURA 8. Germinação (\%) de sementes de calêndula (Calendula officinalis L.) submetidas a diferentes concentrações de ácido salicílico e temperaturas. UNOESTE, Presidente Prudente, SP, 2005.

$\square 0 \mathrm{mM}$ AS $\square 0,025 \mathrm{mM}$ AS $\square 0,05 \mathrm{mM}$ AS

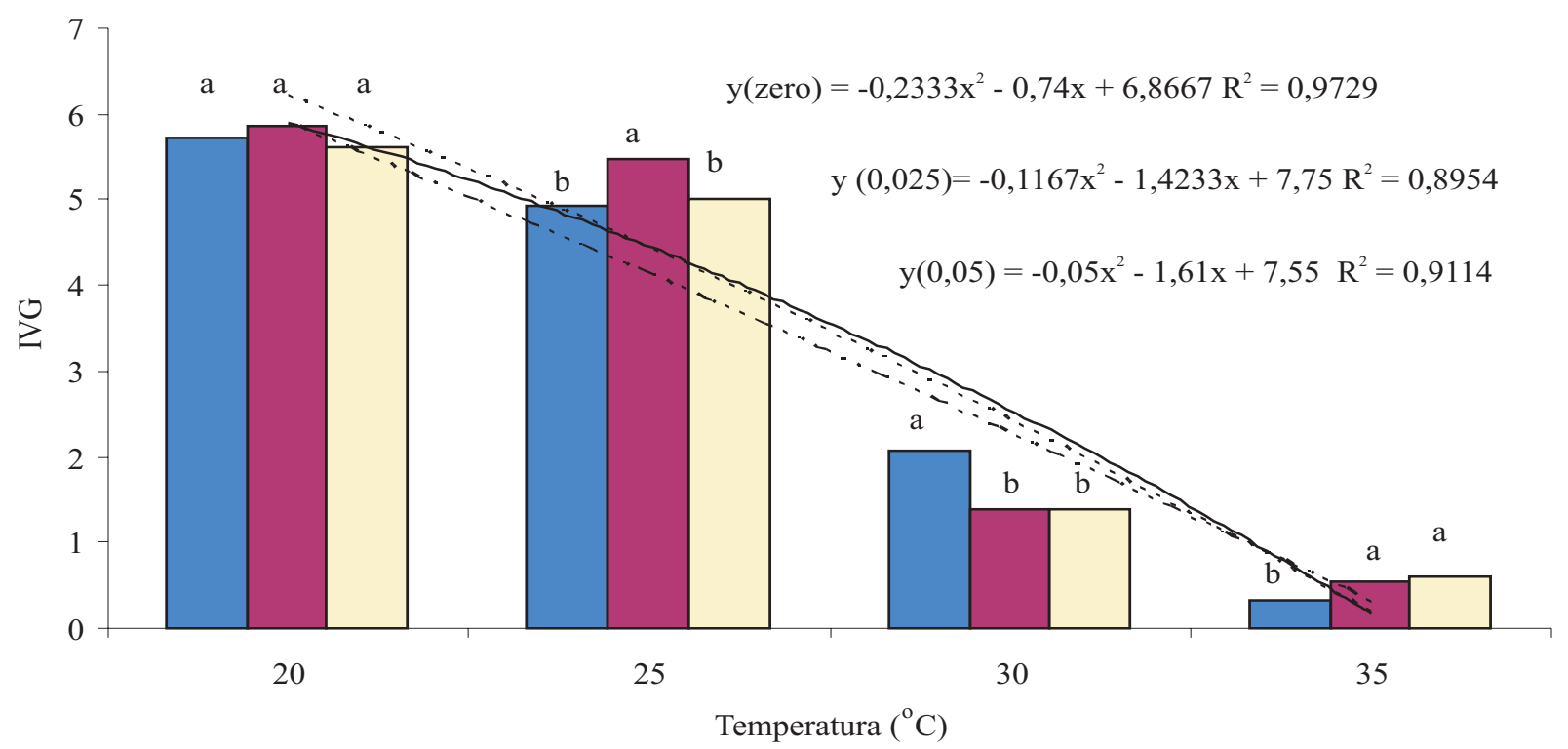

FIGURA 9. Índice de velocidade de germinação (IVG) de sementes de calêndula (Calendula officinalis L.) submetidas a diferentes concentrações de ácido salicílico e temperaturas. UNOESTE, Presidente Prudente, SP,2005.

condições ideais de temperatura $\left(25^{\circ} \mathrm{C}\right)$, observa-se uma melhora significativa com a dose de $0,025 \mathrm{mM}$ de AS. Resultados semelhantes foram registrados por Takaki e Rosim (2000) em Raphanus sativus L.

\section{CONCLUSÃO}

O ácido salicílico na dose de 0,025mM interfere positivamente na percentagem de germinação e no índice de velocidade de germinação de sementes da calêndula em condições ideais e sob efeito de estresse hídrico e térmico a $35^{\circ} \mathrm{C}$.

\section{REFERÊNCIAS}

ANDARWULAN, N.; SHETTY, K. Improvement of pea (Pisum 
sativum) seed vigour response by fish protein hydrolisates in combination with acetyl salicylic acid. Process Biochemistry, Oxford, v.35, p.159-165, 1999.

BAILly, C., BENAMAR, A., CORBINEAU, F., CÔME, D. Free radical scavenging as affected by accelerated ageing and subsequent priming in sunflower seeds. Physiologia Plantarum, Lund, v.104, p.626-652, 1998.

BENHAMOU, N.; NICOLE, M. Cell biology of plant immunization against microbial infection: the potential of induced resistance in controlling plant diseases. Plant Physiology and Biochemistry, Oxford, v.37, n.10, p.703-719, 1999

BRASIL, Ministério da Agricultura e Reforma Agrária. Regras para análise de sementes. Brasília:SNDA/DNDV/CLAV, 1992.365p.

BUSAM, G.; KASSEMEYER, H.-H.; MATTERN, U. Differential expression of chitinases in Vitis vinifera L. responding to systemic acquired resistance activators of fungal challenge. Plant Physiology, Rockville, v.115, p.1029-1038, 1997.

CHAOUI, A.; MAZHOUDI, S.; GHORBAL, M.H.; EL FERZANI, E. Cadmium and zinc induction of lipid peroxidation and effects on antioxidant enzymes activities in bean (Phaseolus vulgaris L.). Plant Science, Madison, v.127, p.139-147, 1997.

FOYER, C.H.; LOPEZ-DELGADO, H.; DAT, J.F.; SCOTT, I.M. Hydrogen peroxide and glutathione-associated mechanisms of acclimatory stress tolerance and signalling. Physiologia Plantarum, Lund, v.100, p.241-254, 1997.

GAZIM, Z.C. Identificação e determinação dos constituintes químicos por cromatografia gasosa acoplada a espectrometria de massa (CG/MS), avaliação da atividade antimicrobiana e aspectos agronômicos do óleo essencial de Calêndula (Calendula oficinalis L. Asteraceae). 2005. 97 f. Dissertação (Mestrado em Ciências Farmaceuticas) - Universidade Estadual de Maringá, Maringá, 2005.

GIANNOPOLITIS, C.N.; RIES, S.K. Superoxide dismutases. 1. Occurrence in higher plants. Plant Physiology, Rockville, v.59, p.309-314, 1977.

GOTO, M. Fundamentals of bacterial plant pathogens. San Diego: Academic Press, 1990. 342p.

GREGGAINS, V.; FINCH-SAVAGE, W.E.; QUICK, W.P.; ATHERTON, N.M. Metabolism-induced free radical activity does not contribute significantly to loss of viability in moist-stored recalcitrant seeds of contrasting species. New Phytologist, Lancaster, v.148, p.267-276, 2000..

HAMMERSCHMIDT, R.; KUC, J. Induced resistance to disease in plants. Boston: Kluwer Academic Pub., 1995. 182 p.

HAMMERSCHMIDT, R., J. KUC. Lignification as a mechanism for induced systemic resistance in cucumber. Physiology of Plant Patholology, Berlin, v.20, p.61-71, 1982.

JUNG, S.; KIM, J.S.; CHO, K.Y.; TAE, G.S.; KANG, B.G. Antioxidant responses of cucumber to photoinhibition and oxidative stress induced by norflurazon under high and low PPFDs. Plant Science, Madison, v.153, p.145-154, 2000.

KÚC, J. Development and future direction of induced systemic resistance in plants. Crop Protection, Oxford, v.19, p.859-861, 2000. LÓPEZ-LÓPEZ, M.J.; LIÉBANA, E.; MARCILLA, P.; BELTRÁ, $\mathrm{R}$. Resistance induced in potato tubers by treatment with acetylsalicylic acid to soft rot produced by Erwinia carotovora subsp. carotovora. Journal of Phytopathology, Gottingen, v.143, p.719-724, 1995.

MACHADO NETO, N. B.; SATURNINO, S. M., BOMFIM, D. C.; CUSTÓDIO, C.C. Water stress induced by mannitol and sodium chloride in soybean cultivars. Brazilian Archives of Biology and Technology, Curitiba, v.47, n. 4, p. 521-529, 2004a.

MACHADO NETO, N. B.; CUSTÓDIO, C. C., GATTI, A. B., PRIOLLI, M.R. e CARDOSO, V. J. M. Proline: use as an indicator of temperature stress in bean seeds. Crop Breeding and Applied Biotechnology, Viçosa, v.4, p.330-337, 2004b.

MAZHOUDI, S.; CHAOUI, A.; GHORBAL, M.H.; EL FERZANI, E. Response of antioxidant enzymes excess copper in tomato (Lycopersicon esculentum Mill). Plant Science, Madison, v.127, p.129-137, 1997.

McCUE, P.; ZHENG, Z.; PINKHAM, J.; SHETTY, K. A model for enhanced pea seedling vigour following low $\mathrm{pH}$ and salicylic acid treatments. Process Biochemistry, Oxford, v.35, p.603-613, 2000.

MÉTRAUX, J. P.; AHL GOY, P.; STAUB, T.; SPELCH, J.; STEINEMANN, A.; RYALS, J.; WARD, E. Induced resistance in cucumber in response to 2,6-dichloroisonicotinic acid and pathogens. In: HENNECKE, H.; VERMA, D.P.S. (Ed). Advances in Molecular Genetics of Plant-Microbe Interactions. Dordrecht: Kluwer Academic Pub., 1991. p.432-439.

NAKAGAWA, J. Testes de vigor baseados no desempenho das plântulas. In: KRZYZANOWSKI, F.C.; VIEIRA, R.D.; FRANÇA NETO, J.B. (Ed.) Vigor de sementes: conceitos e testes. Londrina: ABRATES, 1999. p.2-1 - 2-24.

PALVA, T.K.; HURTIG, M.; DAINDRENAN, P.; PALVA E.T. Salicylic acid induced resistance to Erwinia carotovora subsp. carotovora in tobacco. Molecular Plant-Microbe Interaction, St. Paul, v.7, p.356-363, 1994.

PINHEIRO, M. M.; SANDRONI, M.; LUMMERZHEIM, M.; OLIVEIRA, D.E. A defesa das plantas contra as doenças. Revista Ciência Hoje, São Paulo, v.147, n.1, p. 25-31, 1999.

RIVERO, R.M.; RUIZ, J.M.; GARCIA, P.C.; LÓPEZ-LEFEBRE, E.S.; ROMERO, L. Resistance to cold and heat stress: accumulation of phenolic compounds in tomato and watermelon plants. Plant Science, Madison, v.160, p.315-321, 2001.

SIEGEL, B.Z. Plant peroxidases: an organismic perspective. Plant Growth Regulation, Oxford, v.12, p.303-312, 1993.

STICHER, L.; MAUCH MANI, B.; METRAUX, J.P. Systemic acquired resistance. Annual Review of Phytopathology, Gainesville, v.35, p.235-270, 1997.

SUNG, J.M.; JENG, T.L. Lipid peroxidation and peroxide-scavenging enzymes associated with accelerated aging of peanut seed. Physiologia Plantarum, Lund, v.91, p.51-55, 1994. 
TAKAKI, M.; ROSIM, R.E. Aspirin increases tolerance to high temperature in seeds of Raphanus sativus L. cv Early Scarlet Globe. Seed Science and Technology, Zürich, v.28, n. 1, p.179-183, 2000.
WHITE, R.F. Acetylsalicylic acid (aspirin) induces resistance to tobacco mosaic virus in tobacco. Virology, Oxford, v. 99, p.420$412,1979$.

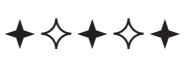

